\title{
Can a physician predict the clinical response to first-line immunomodulatory treatment in relapsing-remitting multiple sclerosis?
}

This article was published in the following Dove Press journal:

Neuropsychiatric Disease and Treatment

19 October 2012

Number of times this article has been viewed

\section{Zsolt Mezei' \\ Daniel Bereczki ${ }^{1,2}$ \\ Lilla Racz' \\ Laszlo Csiba' \\ Tünde Csepany' \\ 'Department of Neurology, \\ University of Debrecen, Debrecen, Hungary; ${ }^{2}$ Department of Neurology, Semmelweis University, Budapest, Hungary}

Video abstract

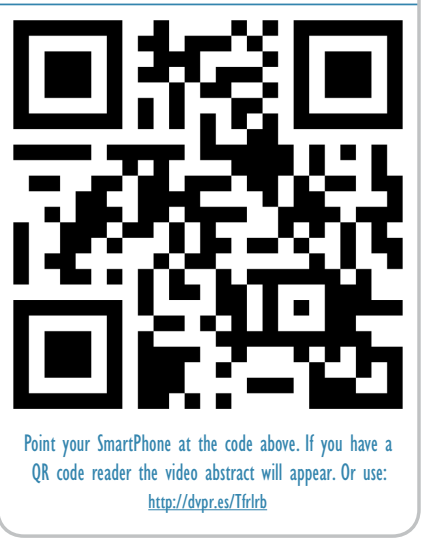

Correspondence: Tünde Csépány Department of Neurology, Medical and Health Science Center, University of Debrecen, Moricz Zs krt 22, Debrecen $\mathrm{H}-4032$, Hungary

Tel $+3652415 \quad 176$

Fax +3652453590

Email csepany@dote.hu
Background: Decreased relapse rate and slower disease progression have been reported with long-term use of immunomodulatory treatments (IMTs, interferon beta or glatiramer acetate) in relapsing-remitting multiple sclerosis. There are, however, patients who do not respond to such treatments, and they can be potential candidates for alternative therapeutic approaches.

Objective: To identify clinical factors as possible predictors of poor long-term response.

Methods: A 9-year prospective, continuous follow-up at a single center in Hungary to assess clinical efficacy of IMT.

Results: In a patient group of 81 subjects with mean IMT duration of $54 \pm 33$ months, treatment efficacy expressed as annual relapse rate and change in clinical severity from baseline did not depend on the specific IMT (any of the interferon betas or glatiramer acetate), and on mono- or multifocal features of the initial appearance of the disease. Responders had shorter disease duration and milder clinical signs at the initiation of treatment. Relapse-rate reduction in the initial 2 years of treatment predicted clinical efficacy in subsequent years.

Conclusion: Based on these observations, we suggest that a 2-year trial period is sufficient to decide on the efficacy of a specific IMT. For those with insufficient relapse reduction in the first 2 years of treatment, a different IMT or other therapeutic approaches should be recommended. Keywords: multiple sclerosis, immunomodulatory, EDSS, relapse, response

\section{Introduction}

Multiple sclerosis (MS) is a lifelong disease affecting young adults that can lead to significant neurological disability. ${ }^{1,2}$ The immunomodulatory treatment (IMT) with interferon (IFN) beta and glatiramer acetate (GA) can favorably affect the disease course in patients with the relapsing-remitting (RR) subtype of MS, by reducing relapse rate compared with placebo and slowing the accumulation of disability as measured by Expanded Disability Status Scale (EDSS) scores. ${ }^{3-6}$ Randomized, controlled trials usually last for 2 years, a relatively short time in a chronic disorder. The primary goal for treatment of patients with MS is slowing or stabilizing the long-term course of the disease. The systematic long-term follow-up of immunomodulatory-treated patients has crucial importance. Long-term studies - including a 5-year placebo-controlled trial with IFN beta-1b, ${ }^{7}$ evaluation of benefit in open-label extension of 2-year placebo-controlled trials with 6 years' subcutaneous IFN beta-1a or 8 years' GA - provide information on safety, clinical, and magnetic resonance imaging outcomes in RRMS. ${ }^{8,9}$ The proportion of noncompleters or dropouts can reach up to $48 \%$ of patients in long-term therapy. ${ }^{10}$ Differences in study designs, study population, or study duration in open-label trials lead to controversial results for the efficacy of different drugs. Early identification of 
patients with a poor response to IMT is important for selecting those patients who are potential candidates to alternative therapeutic approaches.

We present data from a 9-year (1996-2005) prospective, continuous follow-up of IMT at a single center in Debrecen, Hungary. Despite the difficulties associated with any study including a small patient number, our aim with this study was to identify clinical factors as possible predictors of clinical outcomes and contribute to understanding of the impact of continuous treatment of MS.

Our goals were to (1) assess clinical efficacy of IMT on relapses and long-term IMT on disability, (2) evaluate a possible relation of functional disturbances at onset of disorder (unifocal or multifocal clinical symptoms) to response to therapy, (3) evaluate whether clinical characteristics of MS patients when IMT was initiated were different in responders compared with nonresponders to IMT, and (4) evaluate the adherence of patients and tolerability of drugs in long-term treatment.

\section{Patients and methods}

\section{Patients}

Although IFN beta-1b and GA have been available in Hungary since 1996 for treating RRMS patients, intramuscularly (IM) administered IFN beta-1a since 1999 and subcutaneously (SC) administered IFN beta-1a since 2001, the number of treated patients/year was limited by the financial support of the Hungarian National Health Insurance Fund. Most of the patients had to wait for months or years to start their treatment. In most cases, the type of drug was selected by the central committee and not by the treating physicians or patients.

In 1996, we started to treat twelve and 14 RRMS patients with IFN-beta $1 \mathrm{~b}$ and GA, respectively. A total of 81 RRMS patients were selected from $400 \mathrm{MS}$ patients according to the guidelines of the American Academy of Neurology ${ }^{11}$ for IMT at the Department of Neurology of the University of Debrecen up to the end of 2003. Patients were informed, and all signed the informed consent. The study was approved by the review board of the University of Debrecen. The initiation of the treatment differed by IMT agent, as different immunomodulators were approved at different times in Hungary. The criteria for treatment were (1) RR clinical course of MS, (2) clinically or clinically and laboratory-supported definite MS according to the Poser criteria, ${ }^{12}$ (3) an EDSS score of $0-5.5,{ }^{13}(4)$ age $18-50$ years, and (5) at least two relapses in the last 2 years, according to the guidelines of the American Academy of Neurology. ${ }^{11}$ Patients were grouped according to the type and length of IMT and response to treatment in four and three groups, respectively.
Each patient underwent a neurological examination by the same neurologist during the entire follow-up. Disability status was evaluated by the EDSS every 3 months and in the event of a relapse. Patients were seen within 7-14 days of a suspected relapse. Adverse events and laboratory assessments were controlled monthly when IMT was initiated and later every 3 and 6 months, respectively. Patients presenting clinically one or at least two functional system involvements at the time of onset of disorder were grouped as patients with unifocal or multifocal symptoms, respectively. The number of relapses were counted for the 2 years prior to IMT and for the 2 years after the initiation of IMT. Three groups were formed based on the number of relapses during IMT compared with those before IMT. Relapse-free patients, or patients with greater than $50 \%$ reduction in the biennial number of relapses on IMT compared with the 2 years before IMT were grouped as responders. Patients having an identical or higher relapse rate on IMT were considered nonresponders. Patients having 50\% or less biennial reduction compared to the 2 years' pretreatment were defined as partial responders.

Secondary progressive MS was defined as progressive deterioration of disability for at least 12 months and deterioration by at least 1.0 point on the EDSS, not associated with an exacerbation, following the initial RR disease course.

\section{Statistical analysis}

Means \pm standard deviation are reported. Normality of the parameters was checked by the Shapiro-Wilk test. Analysis of variance (ANOVA) or Kruskal-Wallis ANOVA was performed to compare continuous variables between subgroups. For categorical data, the Pearson chi-squared test was used. Statistical significance was considered when $P<0.05$. All statistical analyses were carried out using Statistica (version 5.5) for Windows (StatSoft, Tulsa, USA).

\section{Results}

\section{Patient characteristics}

The baseline data of the clinical subgroups of the 81 patients ( 51 female and 30 male) for the different IMTs are summarized in Table 1. Of the patients, 21 were on IFN beta-1b (Betaferon; Shering, Berlin, Germany) 8 million international units every other day, 26 were on GA (Copaxone; Teva Pharmaceutical Industries, Petah Tikva, Israel) $20 \mathrm{mg}$ every day, 27 were on IM IFN beta-1a (Avonex; Biogen, Cambridge, MA) $30 \mu \mathrm{g}$ each week, and seven were on SC IFN beta-1a (Rebif; Serono, Geneva, Switzerland) $44 \mu \mathrm{g}$ three times a week. None of these patients received other concomitant disease-modifying therapy such as azathioprine or mitoxantrone in this study. 
Table I Baseline data of all patients and groups according to the type of immunomodulatory treatment (IMT)

\begin{tabular}{|c|c|c|c|c|c|c|}
\hline & Total & IFN beta-I b & GA & IFN beta-Ia IM & IFN beta-Ia SC & $P$ (ANOVA) \\
\hline Number & 81 & 21 & 26 & 27 & 7 & \\
\hline Females & 51 & 14 & 18 & 15 & 4 & \\
\hline Mean IMT duration (months) & $54 \pm 33$ & $80 \pm 33$ & $52 \pm 36$ & $38 \pm 20$ & $40 \pm 13$ & $<0.0001$ \\
\hline Age $\pm S D$ at initiation of IMT (years) & $35.3 \pm 8.3$ & $36.0 \pm 8$ & $36.2 \pm 8.3$ & $32.2 \pm 7.1$ & $41.6 \pm 9.8$ & 0.037 \\
\hline $\begin{array}{l}\text { Time between onset and diagnosis } \\
\text { of MS (years) }\end{array}$ & $4 \pm 3.8$ & $2.8 \pm 2$ & $5.0 \pm 5.1$ & $2.9 \pm 2.7$ & $8.1 \pm 3.3$ & 0.0017 \\
\hline $\begin{array}{l}\text { Time between diagnosis and initiation } \\
\text { of IMT (years) }\end{array}$ & $3.8 \pm 3.4$ & $4.5 \pm 4.4$ & $4 . I \pm 3.3$ & $2.9 \pm 2.8$ & $3.6 \pm 2.6$ & NS \\
\hline Prior 2-year relapses & $2.4 \pm 1.3$ & $3.0 \pm 1.1$ & $2.0 \pm 1.7$ & $2.5 \pm 1.1$ & $2.1 \pm 0.9$ & NS \\
\hline Mean baseline EDSS score & $2.8 \pm 1.4$ & $3.4 \pm 1.3$ & $3.1 \pm 1.6$ & $2.1 \pm 1.0$ & $2.6 \pm 1.1$ & 0.011 \\
\hline
\end{tabular}

Abbreviations: IFN, interferon; GA, glatiramer acetate; IM, intramuscular; SC, subcutaneous; ANOVA, analysis of variance; SD, standard deviation; MS, multiple sclerosis; NS, not significant; EDSS, Expanded Disability Status Scale.

There were some differences among the IMT subgroups (1) in age $(P<0.04)$, (2) in elapsed time between onset and clinically definitive diagnosis of MS $(P<0.002)$, and (3) in disability $(P<0.02)$ at initiation of therapy. No differences were seen (1) in the time interval between diagnosis and the initiation of IMT $(P>0.40)$ or $(2)$ in the mean relapse number in the 2 years' pretreatment $(P>0.10)$ (ANOVA). Patients on IM IFN beta-1a treatment were the youngest; they had the shortest time from onset to diagnosis of clinically definite (CD) MS and a lower EDSS score at initiation of IMT (Table 1 and Figure 1).

Mean time on therapy was $54 \pm 33$ months (range 3-112 months). Seven patients discontinued the therapy in the IFN beta-1b-and the GA-treated groups. The RR course changed to a secondary progressive course in seven cases, four out of twelve in the IFN beta-1b group and three out of 14 in the GA group after $13.8 \pm 1.4$ or $20.7 \pm 0$ years' duration of disorder with $6.4 \pm 1.8$ or $7.5 \pm 0.7$ points in EDSS score, respectively. The IMT was changed in three cases.

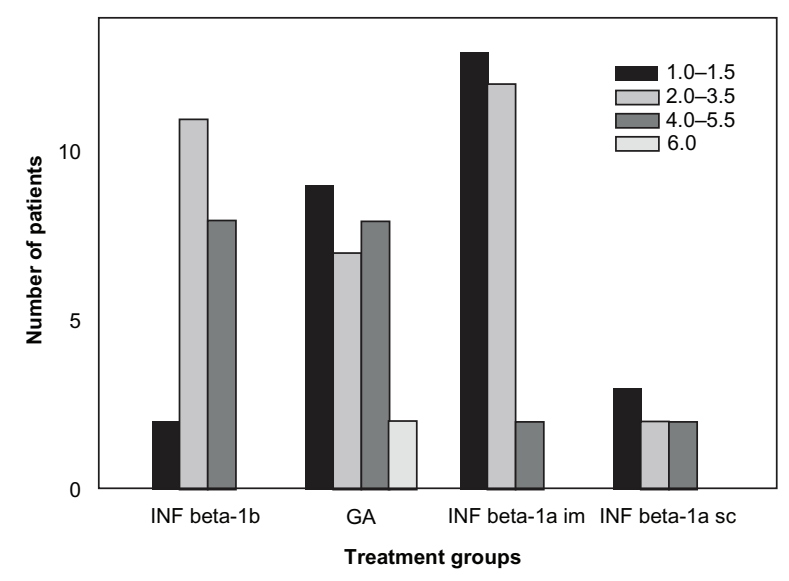

Figure I Distribution of EDSS score at baseline in groups with different immunomodulatory agents.

Abbreviations: EDSS, Expanded Disability Status Scale; INF, interferon; GA, glatiramer acetate.
IFN beta-1b was changed to GA due to lack of efficacy in one case after 1 year's treatment, and one patient from each group shifted from IFN beta- $1 \mathrm{~b}$ and GA injection to the less frequently injected IM IFN beta-1a due to intolerable local side effects and frequent administration, respectively. Two patients developed chest tightness, dyspnea, palpitations, and anxiety as systemic postinjection reaction side effects of GA at the 3-month treatment period. One IM IFN beta-1a-treated patient transiently discontinued the therapy after 2 years due to planned pregnancy. One patient died in nontreatmentrelated GA acute myeloblastic leukemia after 8 years of IMT. In 2005, we still had 17 out of the 26 IFN beta-1b-and GA-treated patients from the original cohort of 1996.

\section{Treatment response}

When evaluating clinical efficacy, the relapse rate in the first 2 years of IMT was compared to the relapse rate in the 2 years prior to the initiation of IMT. When checking the treatment response, there was no sex difference. The mean number of relapses before and during 2 years of IMT is provided in Figure 2. The mean number of relapses decreased by $75 \%$ in the total group and was significantly lower in each group $(P<0.05)$ when compared with the 2 years' pretreatment. The number of relapses was different among the IMT groups in the 2-year pretreatment period ( $P=0.015$, Kruskal-Wallis ANOVA) as well as in the first 2 years on IMT ( $P=0.0028$, Kruskal-Wallis ANOVA), but there were no significant differences in the mean decline in relapses $(P=0.996$, ANOVA). Mean EDSS scores increased by only 0.5 points from $2.8 \pm 1.4$ to $3.3 \pm 2.0$ after $54 \pm 33$ months' therapy in all the patients with $12.2 \pm 6.5$ years' disease duration.

The full length of treatment was different in the groups, because the different IMTs became available at different times. Therefore, we compared the progression by treatment duration with subgroups of 2,4 , and more than 


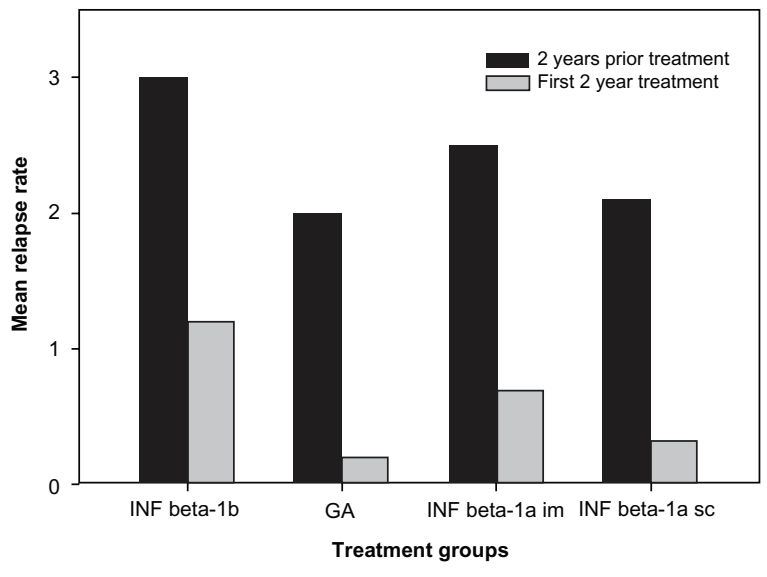

Figure 2 Effect of treatment on relapse numbers in the groups according to the type of immunomodulatory treatment (IMT).

6 years' continuous treatment (Table 2). The total number of patients with more than 6 years' treatment was 29 . The maximal duration of IFN beta-1a SC treatment reached only 5 years.

As mentioned above, the number of relapses and EDSS score differed at baseline among the IMT groups. At the time of initiation of IMT, disability was less pronounced in the IFN-1a IM group, and the difference sustained during the follow-up (2 years, $P<0.026$; 4 years, $P<0.003$; 6 years $P<0.025$ ) (Figure 3 ). The degree of progression in EDSS scores was not different among the groups at 2 years ( $P=0.23)$ or 4 years $(P=0.11)$, and became different only after 6 years $(P=0.003)$ (Table 2$)$.

When the dissemination of clinical symptoms was compared to the clinical course and response to IMT, no difference was found between mono- or multifocal clinical appearance in the age of onset of disorder, in the time required for diagnosis of CDMS, in patients' natural history or change of relapses or long-term progression by mean EDSS change on IMT (Table 3). Patients with multifocal clinical symptoms at onset had a tendency towards higher EDSS scores at baseline than those with unifocal symptoms.

When checking whether responders and nonresponders differ on basic characteristics, we found that the age, relapse rate in the pretreatment period, and the EDSS score at the time of initiation of IMT were not different (Table 4). The time interval between onset and diagnosis of CDMS, and the duration of disorder at the time of initiation of therapy, were also not different between nonresponder and responder patients. Nonresponders developed higher EDSS scores at the second and fourth years of treatment $(P=0.015$ and $P=0.016)$.

Furthermore, we found correlation between age at the time of initiation of IMT and some clinical outcome parameters, such as elapsed time between onset and diagnosis of CDMS $(P<0.0001)$, time interval between diagnosis and initiation of IMT $(P=0.002)$, relapse rate in the prior 2 years of IMT ( $P=0.042)$, and disability according to the mean EDSS score at baseline, and after $2(P<0.0001), 4(P<0.00001)$ or more than 6 years' $(P=0.003)$ treatment.

\section{Tolerability of the immunomodulators}

Injection-site reactions, including local erythema, pain, or skin necrosis generally declined in occurrence during longterm treatment. Surprisingly, these can develop at any time, regardless of the level of skill administering self-injections. The incidences of injection-site reactions and flu-like symptoms are summarized in Table 5. Skin necrosis developed in three cases with IFN beta-1b and in one case with GA over the years. Lipoatrophies were observed after 4 years of treatment. Flu-like symptoms, including headache, fatigue, myalgia, and postinjection fever, requiring medication were consistent in some cases on long-term IMT. Only two patients discontinued the IMT due to intolerable local side effects. The therapy was changed to another drug, requiring less frequent administration.

Table 2 Effect of treatment on EDSS progression in patient subgroups according to the length of continuous immunomodulatory treatment (IMT)

\begin{tabular}{|c|c|c|c|c|c|c|}
\hline & Total & IFN beta-I b & GA & IFN beta-I a IM & IFN beta-I a SC & $P$ (ANOVA) \\
\hline \multicolumn{7}{|l|}{ Patients } \\
\hline 2,4 , and $>6$ years' IMT, respectively & $78,75,29$ & $20,20,16$ & $24,21,7$ & $27,27,6$ & $7,7,0$ & \\
\hline EDSS 2 years' IMT & $2.9 \pm 1.6$ & $3.3 \pm 1.7$ & $3.3 \pm 1.8$ & $2.1 \pm 1.1$ & $2.9 \pm 1.1$ & 0.025 \\
\hline EDSS 4 years' IMT & $3.0 \pm 1.8$ & $3.8 \pm 1.8$ & $3.5 \pm 2.2$ & $2.1 \pm 1.1$ & $2.9 \pm 1.1$ & 0.003 \\
\hline EDSS $>6$ years' IMT & $4.0 \pm 2.2$ & $4.5 \pm 2.1$ & $4.6 \pm 2.1$ & $1.9 \pm 1.4$ & NA & 0.025 \\
\hline EDSS change from baseline at 2 years' IMT & $0.1 \pm 0.7$ & $-0.1 \pm 0.8$ & $0.3 \pm 0.8$ & $0.0 \pm 0.5$ & $0.4 \pm 0.6$ & NS \\
\hline EDSS change from baseline at 4 years' IMT & $0.3 \pm 0.9$ & $0.4 \pm 1.1$ & $0.6 \pm 1.1$ & $-0.1 \pm 0.6$ & $0.3 \pm 0.5$ & NS \\
\hline EDSS change from baseline over 6 years' IMT & $0.9 \pm 1.3$ & $1.1 \pm 1.5$ & $1.1 \pm 1.1$ & $0.2 \pm 0.9$ & NA & 0.003 \\
\hline
\end{tabular}

Abbreviations: IFN, interferon; GA, glatiramer acetate; IM, intramuscular; SC, subcutaneous; ANOVA, analysis of variance; NA, not applicable; NS, not significant; EDSS, Expanded Disability Status Scale. 


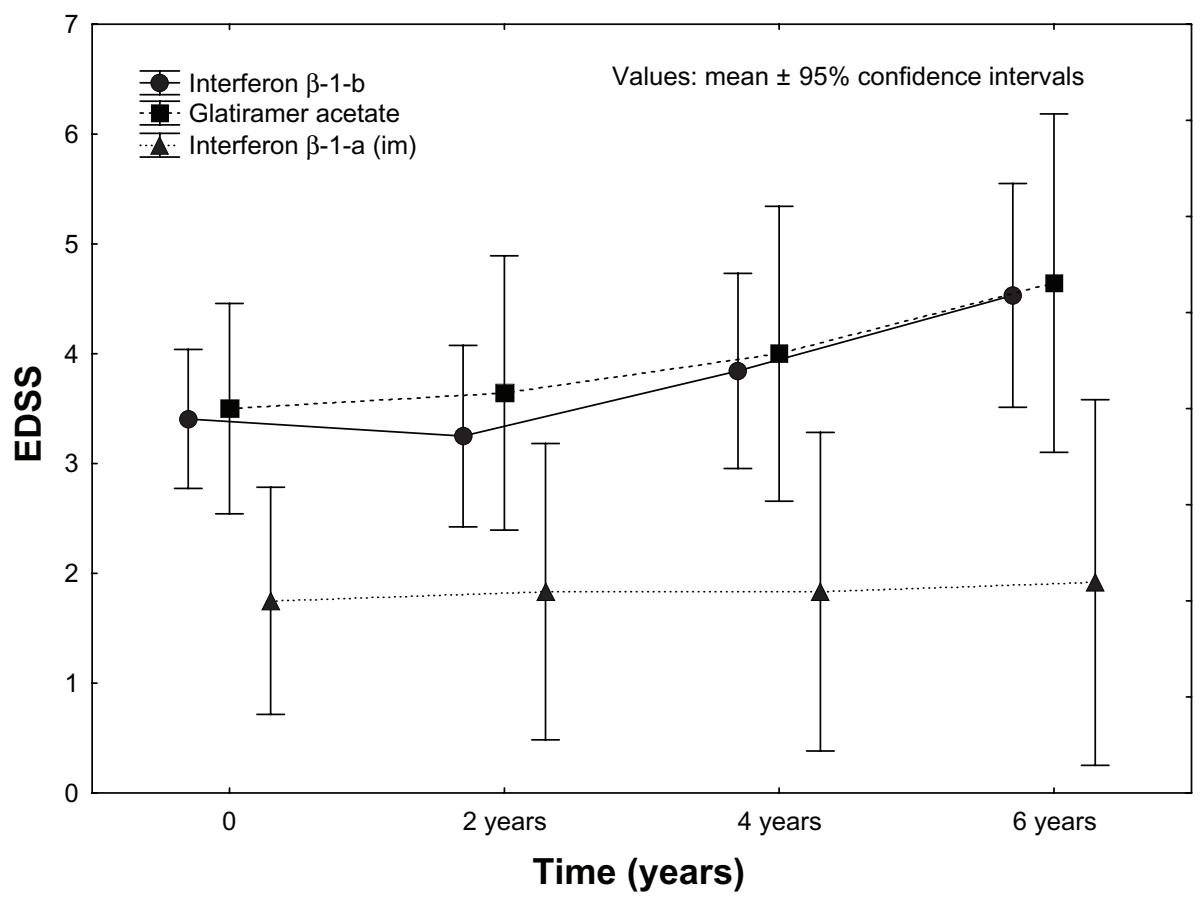

Figure 3 Sustained efficacy of longer than 6 years' immunomodulatory treatment on disability.

Notes: Patients treated with IFN beta- Ia intramuscularly had the smallest Expanded Disability Status Scale (EDSS) score at baseline and 2, 4, and more than 6 years' treatment $(P=0.01 \mathrm{I}, 0.025,0.003$, and 0.025 respectively).

\section{Discussion}

Multiple sclerosis is a chronic disease with potential negative impact on patients' quality of life. Relapses are considered to be the clinical manifestation of acute inflammatory demyelination in the central nervous system, whereas progression

Table 3 Baseline data of patients and treatment response in the groups according to clinical presentation at onset of multiple sclerosis (MS)

\begin{tabular}{lcc}
\hline & $\begin{array}{l}\text { Unifocal } \\
\text { symptom } \\
(\mathbf{n}=\mathbf{4 6})\end{array}$ & $\begin{array}{l}\text { Multifocal } \\
\text { symptoms } \\
\mathbf{( n = 3 5 )}\end{array}$ \\
\hline $\begin{array}{l}\text { Time between onset and } \\
\text { diagnosis of MS (years } \pm \text { SD) }\end{array}$ & $3.9 \pm 3.5$ & $4.1 \pm 4.4$ \\
$\begin{array}{l}\text { Time between diagnosis and } \\
\text { initiation of IMT (years } \pm \text { SD) }\end{array}$ & $3.4 \pm 2.7$ & $4.2 \pm 4.2$ \\
$\begin{array}{l}\text { Age } \pm \text { SD at initiation } \\
\text { of IMT (years) }\end{array}$ & $35.3 \pm 2.8$ & $35.2 \pm 8.5$ \\
$\begin{array}{l}\text { Prior 2-year relapses } \\
\text { Relapses in first 2 years' IMT }\end{array}$ & $2.3 \pm 0$ & $2.5 \pm 0.7$ \\
$\begin{array}{l}\text { Mean baseline EDSS } \\
\text { score ( } \pm \text { SD) }\end{array}$ & $0.5 \pm 0$ & $0.7 \pm 2.8$ \\
$\begin{array}{l}\text { Mean IMT duration } \\
\text { (months } \pm \text { SD) }\end{array}$ & $2.6 \pm 2.1$ & $3.0 \pm 0.3$ \\
Final duration of disorder & $59 \pm 35$ & $47 \pm 30$ \\
with IMT & $12.3 \pm 5.8$ & $12.2 \pm 7.3$ \\
$\begin{array}{l}\text { Final EDSS on IMT } \\
\text { EDSS on >6 years' IMT }\end{array}$ & $3.1 \pm 2.0$ & $3.6 \pm 2.1$ \\
\hline
\end{tabular}

Abbreviations: IMT, immunomodulatory treatment; SD, standard deviation; EDSS, Expanded Disability Status Scale. is considered to reflect chronic demyelination, gliosis, and axonal loss. To date, there are only four approved diseasemodifying agents (DMAs) as first-line treatment options for slowing the progression of the disorder. ${ }^{14}$ The efficacy of DMAs can be evaluated by the change in the number of relapses in a relatively short period of time, but long-term treatments are needed to estimate their efficacy on disease process. EDSS is a simple method to monitor disease progression clinically.

The first aim of our study was to show the benefits of different IMTs in MS administered over a long period. As it is difficult to perform a placebo-controlled study when we have an effective treatment, we applied a self-control design, where the number of relapses in the first 2 years of treatment was compared to the relapse numbers in the same patient in the 2 years prior to initiation of IMT. In our series, the relapse rate at the 2-year follow-up period was reduced by more than $60 \%$ compared to the 2 years' pretreatment, regardless of the type of treatment. The reduction in relapse rate was higher than observed in pivotal trials comparing IMT with placebo, ${ }^{3-6}$ but consistent with findings in open-label studies. ${ }^{15-19}$

We observed a moderate progression of disability over 4 years in the total patient population, and about $10 \%$ of patients became secondary progressive over a 12 -year course of the disorder, which is less than expected from natural history data. ${ }^{20}$ 
Table 4 Long-term effect of immunomodulatory treatment (IMT) on EDSS change in the groups according to short-term response to IMT by relapse numbers

\begin{tabular}{|c|c|c|c|c|}
\hline & $\begin{array}{l}\text { Responders } \\
(\mathrm{n}=\mathbf{5 8})\end{array}$ & $\begin{array}{l}\text { Nonresponders } \\
(n=8)\end{array}$ & $\begin{array}{l}\text { Partial responders } \\
(n=15)\end{array}$ & $\mathbf{P}$ \\
\hline Time between onset and diagnosis of MS (years) & $3.9 \pm 8.1$ & $4.8 \pm 6.0$ & $3.9 \pm 7.4$ & NS \\
\hline Time between diagnosis and initiation of IMT (years) & $3.3 \pm 3.5$ & $5.6 \pm 1.1$ & $4.6 \pm 0$ & NS \\
\hline Mean IMT duration (months) & $55 \pm 33$ & $42 \pm 28$ & $57 \pm 36$ & NS \\
\hline Final duration of disorder & $11.8 \pm 8.5$ & $13.8 \pm 8.1$ & $13.1 \pm 6.7$ & NS \\
\hline Final EDSS score on IMT & $3.0 \pm 2.0$ & $4.6 \pm 2.4$ & $4.0 \pm 1.6$ & 0.032 \\
\hline Age $\pm S D$ at initiation of IMT (years) & $35.8 \pm 13.4$ & $34.9 \pm 7.8$ & $33.6 \pm 2.1$ & NS \\
\hline Prior 2-year relapses & $2.5 \pm 0.7$ & $2.1 \pm 1.4$ & $2.5 \pm 0.7$ & NS \\
\hline Relapses in first 2 years' IMT & $0.2 \pm 0$ & $1.9 \pm 1.4$ & $1.5 \pm 0.7$ & $<0.0001$ \\
\hline Mean baseline EDSS score & $2.6 \pm 0.7$ & $3.1 \pm 1.8$ & $3.2 \pm 0.7$ & NS \\
\hline EDSS score, 2 years' IMT & $2.5 \pm 0.4$ & $3.7 \pm 2.1$ & $3.7 \pm 0.7$ & 0.015 \\
\hline EDSS score, 4 years' IMT & $2.6 \pm 0.4$ & $4.3 \pm 0.7$ & $3.9 \pm 0.4$ & 0.016 \\
\hline EDSS score, $>6$ years' IMT & $3.6 \pm 0.4(n=2 I)$ & $7.5(n=1)$ & $4.9(n=7)$ & NS \\
\hline
\end{tabular}

Abbreviations: SD, standard deviation; MS, multiple sclerosis; NS, not significant; EDSS, Expanded Disability Status Scale.

Pivotal trials reported that both IFN beta-1a preparations were associated with significant increases in time to sustained disability progression in patients with relapsing MS, ${ }^{5,6}$ whereas IFN beta- $1 \mathrm{~b}$ and GA were not associated with a significant benefit on this end point. ${ }^{3,4}$ Head-to-head, open-label studies have compared the efficacy and tolerability of IFN beta products and GA for the treatment of relapsing MS. Results of these studies are conflicting, with most suggesting equivalent clinical effects of IFN beta products $^{17,21-25}$ but some have shown small treatment differences among the agents, such as potential benefit of GA over IFNs ${ }^{26}$ or SC IFN beta-1a over IM IFN beta-1a in the Evidence of Interferon Dose Response: European North American Comparative Efficacy study ${ }^{18}$ or potential benefit of SC IFN beta-1b over IM IFN beta-1a in the Independent Comparison of Interferons trial. ${ }^{27}$ Although the patients in our study were quasi-randomized to different DMAs (patient allocation was decided by medication availability and not by the physician's decision), they differed in some of the baseline demographics and disease characteristics. Regardless of these differences, the progression of disability was not

Table 5 Incidences of side effects of immunomodulatory drugs

\begin{tabular}{lllll}
\hline & $\begin{array}{l}\text { IFN } \\
\text { beta-Ib } \\
(\mathbf{n}=\mathbf{2 I})\end{array}$ & $\begin{array}{l}\text { GA } \\
(\mathbf{n}=\mathbf{2 6})\end{array}$ & $\begin{array}{l}\text { IFN } \\
\text { beta-Ia IM } \\
(\mathbf{n}=\mathbf{2 7})\end{array}$ & $\begin{array}{l}\text { IFN } \\
\text { beta-Ia SC } \\
(\mathbf{n}=\mathbf{7})\end{array}$ \\
\hline $\begin{array}{l}\text { Injection- } \\
\text { site reaction }\end{array}$ & 6 & 3 & 0 & $\mathrm{I}$ \\
$\begin{array}{l}\text { Lipoatrophy } \\
\text { Flu-like }\end{array}$ & 2 & $\mathrm{I}$ & 0 & $\mathrm{I}$ \\
symptoms & 6 & 0 & 5 & 3 \\
\hline
\end{tabular}

Abbreviations: IFN, interferon; GA, glatiramer acetate; IM, intramuscular; SC, subcutaneous. different among the different treatment groups, suggesting similar efficacy of the different agents over the course of the disorder. This finding suggests that the frequency of relapses is an important indicator of the efficacy of these IMTs.

Data from the Controlled High-Risk Avonex Multiple Sclerosis, Controlled High-Risk Avonex Multiple Sclerosis Prevention Study in Ongoing Neurologic Surveillance, and Early Treatment of MS studies clearly demonstrate important clinical and MRI benefits of early IFN beta therapy in patients with syndromes that are suggestive of early disease. ${ }^{28-30}$ In our study, patients receiving IM IFN beta-1a treatment had the lowest disability scores after 6 years' therapy with 11 years' duration of disorder. The elapsed time to develop CDMS was the same in the IM IFN beta-1a as the INF beta-1b group. The IMT was started slightly later in the IFN beta- $1 \mathrm{~b}$ group than the IM IFN beta-1a group, when the patients had deteriorated already and become more disabled in the INF beta- $1 \mathrm{~b}$ than the IM IFN beta-1a group, with the same duration of disorder supporting potential benefit of early disease treatment.

We did not find any difference or prognostic value of unifocal or multifocal presentation of MS onset in the time required to develop CDMS or to predict treatment response. Investigators in the Betaferon/Betaseron in Newly Emerging MS for Initial Treatment study studied the effects of IFN beta-1b in patients who had unifocal or multifocal neurological syndromes. The subgroup analysis revealed a stronger treatment effect in patients with monofocal clinical presentation and fewer $T_{2}$ lesions, indicating that treatment was particularly beneficial in patients with less active or disseminated disease. ${ }^{31}$ Our patients, presenting unifocal or multifocal symptoms, had been grouped clinically and disseminated already at the time of IMT initiation. IMT was 
introduced slightly later in patients with multifocal symptoms when mean EDSS score was slightly higher than patients with unifocal initiation of MS. Comparing data of other Hungarian centers with ours, the progression by EDSS after 6 years' treatment was less pronounced when the baseline EDSS score was lower. ${ }^{16}$

Discontinuation/switch rates were $44 \%$ for GA, $36.5 \%$ for IFN beta-1b, $20.9 \%$ for SC IFN beta-1a and $18.3 \%$ for IM IFN beta-1a according to the results of a Danish registry study, when $52 \%$ of patients were still receiving their initiation therapy ${ }^{27}$ after 7 years. There was excellent adherence to IMT in our study, similar to another Hungarian center. ${ }^{16}$ The percentage of patients who dropped out of our follow-up study before reaching the secondary progressive course was remarkably low. The consistent side effects of IMT varied between $10 \%$ and $35 \%$, most frequently associated with SC IFN administration. Lipoatrophy usually associated with GA treatment was also observed with other types of SC IMT, as reported by others, ${ }^{32}$ and all of them occurred in females.

A relapsing course is followed by chronic progression in some $80 \%$ of the cases within 2 decades, and median times to reach EDSS scores of 6, 8, and 10 of 12.7, 20.6, and 43.9 years, respectively, were reported in natural history cohorts by Kremenchutzky et al, with the great majority of RR patients entering a progressive phase with a mean time to progression of 10.4 years. ${ }^{20}$ Our patients required longer disease duration to convert their course to a secondary progressive phase, but our patient sample was too small to make a strong conclusion. Comparing natural history cohorts from London, Ontario, and the UK with our results, our patients demonstrated the benefit of IMT, wherein they still have mild disability after more than a 12-year course of disorder, better than expected from the natural history data.

Suppressing relapses by disease modifying agents (DMA) influenced the progression of irreversible disability in our patients, conflicting with Lyon MS cohort data. ${ }^{33}$ Our nonresponders continuously progressed. Irreversible neurological disability accumulated faster in a relapse reductiondependent manner. This supports the classical concept of inflammation playing a role leading to neurodegeneration in MS. Compared with nonresponders, responders were older and had longer disease duration and a higher relapse rate during the year prior to IFN beta therapy. ${ }^{34}$ Our patients didn't differ in age or relapse rate at the time IMT was initiated, and nonresponders had only a slightly longer disease duration than responders, probably due to the small patient sample size of our cohort.
Clinicians now have the tools to manage the course of RRMS more effectively with the advent of highly active second-line therapies. ${ }^{34,35}$ Treatment optimization based on clinical response to first-line therapies can guide the neurologist in more active management of the early course of RRMS. Predictors of poor response to IFN beta have been suggested in several studies. ${ }^{36-40}$ Worsening of disability appears the most reliable indicator for long-term efficacy, which associated with the relapse number during the early phase of IMT in our patients. When cost-effective home administration of intravenous methylprednisolone becomes a future application by community-based neurologists, ${ }^{41}$ recording the number of clinical attacks could be a simple measure for evaluating treatment efficacy in daily practice.

Our results, derived from a single center with a small cohort size, are consistent with larger, well-controlled phase III clinical trials and observational studies that have shown equal efficacy among beta IFN products ${ }^{17}$ and GA, ${ }^{25}$ probably not only in the short term but in long-term treatment as well, particularly with higher benefit in patients with mild disability and shorter course of disorder at the time of IMT initiation. Relapse-rate reduction in the initial 2 years of treatment predicted clinical efficacy in subsequent years. Based on these observations, we suggest that a 2-year trial period is sufficient to decide on the efficacy of a specific IMT. For those with insufficient relapse reduction in the first 2 years of treatment, a different IMT or other therapeutic approaches should be recommended.

\section{Acknowledgments}

The work was partly supported by grant no TAMOP-4.2.1. B-09/1/KMR. We thank Jánosné Virág for her contribution to this work.

\section{Disclosure}

The authors report no conflicts of interest in this work.

\section{References}

1. Weinshenker BG, Ebers GC. The natural history of multiple sclerosis. Can J Neurol Sci. 1987;14:255-261.

2. Weinshenker BG. The natural history of multiple sclerosis. Neurol Clin. 1995;13:119-146.

3. [No authors listed]. Interferon beta- $1 \mathrm{~b}$ is effective in relapsing-remitting multiple sclerosis: I. Clinical results of a multicenter, randomized, double-blind, placebo-controlled trial. The IFNB Multiple Sclerosis Study Group. Neurology. 1993;43:655-661.

4. Johnson KP, Brooks BR, Cohen JA, et al. Copolymer 1 reduces relapse rate and improves disability in relapsing-remitting multiple sclerosis: results of a phase III. multicenter, double-blind placebo-controlled trial. The Copolymer 1 Multiple Sclerosis Study Group. Neurology. 1995;45: $1268-1276$. 
5. Jacobs LD, Cookfair D, Rudick R, et al. Intramuscular interferon beta-1a for disease progression in relapsing multiple sclerosis. Ann Neurol. 1996;39:285-294.

6. [No authors listed]. Randomised double-blind placebo-controlled study of interferon beta-1a in relapsing remitting multiple sclerosis. PRISMS (Prevention of Relapses and Disability by Interferon beta-1a Subcutaneously in Multiple Sclerosis) Study Group. Lancet. 1998; 352:1498-1504.

7. [No authors listed]. Interferon beta-1b in the treatment of multiple sclerosis: final outcome of the randomized controlled trial. The IFNB Multiple Sclerosis Study Group and The University of British Columbia MS/MRI Analysis Group. Neurology. 1995;45:1277-1285.

8. Kappos L, Traboulsee A, Constantinescu C, et al. Long-term subcutaneous interferon beta-1a therapy in patients with relapsing-remitting MS. Neurology. 2006;67:944-953.

9. Johnson KP, Ford CC, Lisak RP, Wolinsky JS. Neurologic consequence of delaying glatiramer acetate therapy for multiple sclerosis: 8-year data. Acta Neurol Scand. 2005;111:42-47.

10. Sorensen PS, Koch-Henriksen N, Ravnborg M, et al. Immunomodulatory treatment of multiple sclerosis in Denmark: a prospective nationwide survey. Mult Scler. 2006;12:253-264.

11. [No authors listed]. Practice advisory on selection of patients with multiple sclerosis for treatment with Betaseron. Report of the Quality Standards Subcommittee of the American Academy of Neurology. Neurology. 1994;44:1537-1540.

12. Poser CM, Paty DW, Scheinberg L, et al. New diagnostic criteria for multiple sclerosis: guidelines for research protocols. Ann Neurol. 1983;13:227-231.

13. Kurtzke JF. Rating neurologic impairment in multiple sclerosis: an expanded disability status scale (EDSS). Neurology. 1983;33: 1444-1452.

14. Syed RA, Mark AA. Current approved options for treating patients with multiple sclerosis. Neurology. 2004;63:S8-S14.

15. Noseworthy JH, Ebers GC, Vandervoort MK, Farquhar RE, Yetisir E, Roberts R. The impact of blinding on the results of a randomized, placebo-controlled multiple sclerosis clinical trial. Neurology. 1994;44: 16-20.

16. Bencsik K, Fuvesi J, Fricska-Nagy Z, et al. Short communication: treatment of relapsing-remitting multiple sclerosis patients with IFNbeta1b: results of a 6-year follow-up. J Interferon Cytokine Res. 2006;26: 96-100.

17. Limmroth V, Malessa R, Zettl UK, et al. Quality Assessment in Multiple Sclerosis Therapy (QUASIMS): a comparison of interferon beta therapies for relapsing-remitting multiple sclerosis. J Neurol. 2007;254:67-77.

18. Panitch H, Goodin DS, Francis G, et al. Randomized, comparative study of interferon $\beta$-1a treatment regimens in MS. The EVIDENCE trial. Neurology. 2002;59:1496-1506.

19. Freedman MS. Long-term follow-up of clinical trials of multiple sclerosis therapies. Neurology. 2011;76:S26-S34.

20. Kremenchutzky M, Rice GP, Baskerville J, Wingerchuk DM, Ebers GC. The natural history of multiple sclerosis: a geographically based study 9: observations on the progressive phase of the disease. Brain. 2006;129:584-594.

21. Milanese C, La Mantia L, Palumbo R, et al. A post-marketing study on interferon $\beta \mathrm{lb}$ and $1 \mathrm{a}$ treatment in relapsing-remitting multiple sclerosis: different response in drop-outs and treated patients. J Neurol Neurosurg Psychiatry. 2003;74:1689-1692.

22. Miralles AA, Fuentes B, Barreiro P, Diez-Tejedor E. Comparative clinical efficacy analysis between interferon beta 1-b and interferon beta 1-a. J Neurol. 2000;247:III139.

23. Öztekin N, Öztekin MF. An open-label trial comparing the effects of IFNß-1a (Rebif), (Avonex), and IFNß-1b (Betaferon) on the relapse rate, lesion load on MRI and disease progression in patients with relapsing-remitting multiple sclerosis: results of 24 months of therapy. Mult Scler. 2001;7:S96.
24. Trojano M, Liguori M, Paolicelli D, et al. Interferon beta in relapsingremitting multiple sclerosis: an independent postmarketing study in southern Italy. Mult Scler. 2003;9:451-457.

25. Mikol DD, Barkhof F, Chang P, et al. Comparison of subcutaneous interferon beta-1a with glatiramer acetate in patients with relapsing multiple sclerosis (the REbif vs Glatiramer Acetate in Relapsing MS Disease [REGARD] study): a multicentre, randomised, parallel, openlabel trial. Lancet Neurol. 2008;7:903-914.

26. Haas J, Firzlaff M. Twenty-four-month comparison of immunomodulatory treatments - a retrospective open label study in 308 RRMS patients treated with beta interferons or glatiramer acetate (Copaxone). Eur $J$ Neur. 2005;12:425-431.

27. Durelli L, Verdun E, Barbero P, et al. Every-other-day interferon beta-1b versus once-weekly interferon beta- $1 \mathrm{~b}$ for multiple sclerosis: results of a 2-year prospective randomised multicentre study (INCOMIN). Lancet. 2002;359:1453-1460.

28. Jacobs LD, Beck RW, Simon JH, et al. Intramuscular interferon beta-1a therapy initiated during a first demyelinating event in multiple sclerosis. N Engl J Med. 2000;343:898-904.

29. Kinkel RP, Kollman C, O'Connor P, et al. IM interferon beta-1a delays definite multiple sclerosis 5 years after a first demyelinating event. Neurology. 2006;66:678-684.

30. Comi G, Filippi M, Barkhof F, et al. Effect of early interferon treatment on conversion to definite multiple sclerosis: a randomised study. Lancet. 2001;357:1576-1582.

31. Kappos L, Polman CH, Freedman MS, et al. Treatment with interferon beta-1b delays conversion to clinically definite and McDonald MS in patients with clinically isolated syndromes. Neurology. 2006;67: 1242-1249.

32. Beiske AG, Myhr KM. Lipoatrophy: a non-reversible complication of subcutaneous interferon-beta 1a treatment of multiple sclerosis. J Neurol. 2006;253:377-378.

33. Confavreux C, Vukusic S. Accumulation of irreversible disability in multiple sclerosis: from epidemiology to treatment. Clin Neurol Neurosurg. 2006;108:327-332.

34. Hutchinson M. Predicting and preventing the future: actively managing multiple sclerosis. Pract Neurol. 2009;9:133-143, discussion 144.

35. Limmroth V, Putzki N, Kachuck NJ. The interferon beta therapies for treatment of relapsing-remitting multiple sclerosis: are they equally efficacious? A comparative review of open-label studies evaluating the efficacy, safety, or dosing of different interferon beta formulations alone or in combination. Ther Adv Neurol Disord. 2011;4: 281-296.

36. Waubant E, Vukusic S, Gignoux L, et al. Clinical characteristics of responders to interferon therapy for relapsing MS. Neurology. 2003;61: 184-189.

37. Río J, Nos C, Tintoré M, et al. Defining the response to interferon-beta in relapsing-remitting multiple sclerosis patients. Ann Neurol. 2006;59: 344-352.

38. Pozzili C, Prosperini L. Clinical markers of therapeutic response to disease modifying drugs. Neurol Sci. 2008;29:S211-S213.

39. Río J, Castilló J, Rovira A, et al. Measures in the first year of therapy predict the response to interferon $\{$ beta $\}$ in MS. Mult Scler. 2009;15: 848-853.

40. Prosperini L, Gallo V, Petsas N, Borriello G, Pozzilli C. One-year MRI scan predicts clinical response to interferon beta in multiple sclerosis. Eur J Neurol. 2009;16:1202-1209.

41. Créange A, Debouverie M, Jaillon-Rivière V, et al. Home administration of intravenous methylprednisolone for multiple sclerosis relapses: the experience of French multiple sclerosis networks. Mult Scler. 2009;15:1085-1091. 
Neuropsychiatric Disease and Treatment

Dovepress

\section{Publish your work in this journal}

Neuropsychiatric Disease and Treatment is an international, peerreviewed journal of clinical therapeutics and pharmacology focusing on concise rapid reporting of clinical or pre-clinical studies on a range of neuropsychiatric and neurological disorders. This journa is indexed on PubMed Central, the 'PsycINFO' database and CAS.

The manuscript management system is completely online and includes a very quick and fair peer-review system, which is all easy to use. Visit http://www.dovepress.com/testimonials.php to read real quotes from published authors.

Submit your manuscript here: http://www.dovepress.com/neuropsychiatric-disease-and-treatment-journal 